Kuhlmann, E., Batenburg, R., Groenewegen, P.P., Larsen, C. Bringing a European perspective to the health human resources debate: a scoping study. Health Policy: 2013, 110(1), 6-13

nivel

\begin{tabular}{|l|l|}
\hline $\begin{array}{l}\text { Postprint } \\
\text { Version }\end{array}$ & 1.0 \\
\hline Journal website & $\underline{\text { http://www.healthpolicyirnl.com/article/S0168-8510(12)00298-9/abstract }}$ \\
\hline Pubmed link & $\underline{\text { http://www.ncbi.nlm.nih.gov/pubmed/23200603 }}$ \\
\hline DOI & $10.1016 / j . h e a l t h p o l .2012 .11 .002$ \\
\hline
\end{tabular}

This is a NIVEL certified Post Print, more info at http://www.nivel.eu

\title{
Bringing a European perspective to the health human resources debate: A scoping study
}

\author{
Ellen KuhlmanN ${ }^{\mathrm{A}, \star}$, Ronald BatenbuRG ${ }^{\mathrm{B}}$, Peter P. GROENEWEGEN ${ }^{\mathrm{B}, \mathrm{D}, \mathrm{E}}$, CHRista \\ LARSEN $^{\text {A }}$ \\ ${ }^{\text {A }}$ Department of Social and Policy Sciences, University of Bath, UK \\ ${ }^{\mathrm{b}}$ Netherlands Institute for Heath Services Research (NIVEL), Utrecht, The Netherlands \\ ${ }^{c}$ Institut für Wirtschaft, Arbeit und Kultur (IWAK), Goethe-University Frankfurt, Germany \\ ${ }^{d}$ Department of Sociology, Utrecht University, Utrecht, The Netherlands \\ e Department of Human Geography, Utrecht University, Utrecht, The Netherlands
}

\begin{abstract}
Healthcare systems across the world are increasingly challenged by workforce shortages and misdistribution of skills. Yet, no comprehensive European approach to health human resources (HHR) policy exists and action remains fragmented. This scoping study seeks to contribute to the debates by providing an overview of existing HHR research, and by exploring the challenges of a European approach with a focus on workforce planning. In terms of methods, we build on a scoping review comprising literature analysis and qualitative data gathered from policy experts. In our analysis we observe an overall lack of integrated HHR approaches as major obstacle of efficient HHR planning, and find that five dimensions of integration in HHR policy are needed: system, occupational, sector, gender, and sociocultural integration. Increasing the analytical complexity of HHR planning models does not automatically bring about more reliable and efficient planning, as the added value of these models is highly context-dependent. Yet Europe is highly diverse and we therefore argue the need for a strategic HHR perspective that is capable of bridging many different HHR policies and planning systems, and combining national and European solutions efficiently.
\end{abstract}

\section{INTRODUCTION}

Healthcare systems across the world are increasingly challenged by workforce shortages and misdistribution of skills [1,2]. In Europe, it is expected that the healthcare sector will be confronted with a huge shortage - up to one to two million - of healthcare professionals by 2020 [3]. 
Also, the future skill-mix is expected to be incongruent with the development of healthcare needs [4]. Healthcare consumers are changing due to demographic, epidemiological and socio-cultural developments. At the same time, the size and composition of the health workforce are also changing as a result of changing gender relations and professional, organisational and technological developments. For many countries this implies that the (quantitative and qualitative) match between healthcare demand and supply will be increasingly difficult to achieve and to sustain.

Such scenarios have rung the bells of policymakers [5,6]. Yet a specific European approach to health human resources (HHR) is still poorly developed and no comprehensive data and monitoring systems exist. Contemporary efforts towards establishing and advancing HHR policy are mainly driven by global organisations and often focused on developing countries [2,7-11]. Within the western world, HHR issues are mostly addressed in Anglo-Saxon countries and therefore heavily biased towards North America and/or towards National Health Service (NHS) systems (United Kingdom and Australia) with workforce planning relying on the inflow of professionals from abroad [12-24].

Remarkably, so far no specific European approach to HHR policy has been developed. This is especially surprising because European Union (EU) labour market regulation - together with the east-west push and pull factors - have created specific incentives towards cross-border mobility and migration of health professionals between the member states and candidate countries [3,25]. Taken together, this picture drawn from the international and scholarly HHR debates suggests that there is a need for HHR approaches and empirical research that adequately reflect the situation of Europe and the interdependencies between European countries. Recently, there have been attempts to bring a European perspective to the HHR debates that contributed to the awareness of the challenges of projected workforce shortages and imbalances [3,26-31]. This article builds upon these contributions by presenting a scoping study $[32,33]$. We seek to contribute to the debate by providing an overview of research on HHR, and by an exploration of the challenges and chances of HHR policy in Europe.

Bringing a 'European perspective' to HHR research and policy may start with the countries of the European Economic Area and Switzerland that can to some extend build on joint regulation and policies, but should aim towards an expansion into the WHO European region. We suggest using the term 'health human resources' rather than 'human resources for health'; the latter term is often used in the international literature but linked to a specific WHO programme and policy strategy [2,7] and therefore less appropriate for our purpose. We refer to HHR and HHR policy as an umbrella concept that includes different strands of governing, managing and planning the health workforce.

Hence, there is no uniform definition of HHR policy in the literature and the different strands of HHR may have overlaps. In Box 1 we therefore summarise the proposed terminology and analytical distinction used in this article.

The article begins with mapping the field of existing approaches and research into HHR policy. We then turn our attention towards the challenges and chances of HHR policy in Europe. We briefly describe the situation of research on HHR issues and then discuss the need for an integrated approach to HHR. We conclude by discussing our results with respect to future HHR research and the possibilities of developing an integrated European comparative approach to HHR policy. 
Kuhlmann, E., Batenburg, R., Groenewegen, P.P., Larsen, C. Bringing a European perspective to the health human resources debate: a scoping study. Health Policy: 2013, 110(1), 6-13

\section{MeThodology}

We build on a scoping review of the literature. Following the definitions by Arksey and O’Malley [32] this seems useful considering our goals to (1) evaluate existing research on the topic of HHR, (2) to summarise and disseminate research findings, and (3) to identify gaps in the literature.

Here, we focus on the gap analysis that serves as a springboard towards more explorative approaches.

While a scoping review complies with the meta-analysis and systematic reviews approach, no quality criteria for exclusion and inclusion are used. Instead, all relevant studies are explored to identify key themes. Most importantly for our purpose, a scoping review may also include qualitative and explorative dimensions, such as personal experience and the consultation of experts and stakeholders to improve context-sensitivity of the results. As highlighted by Arksey and O’Malley [32], this provides valuable information and especially helps to identify and complement gaps in the literature and to validate findings, thus contributing to an innovative approach in response to contemporary challenges of comparative health policy [34,35].

Our scoping study comprises three steps: 1 . identifying key policy documents and HHR approaches in the international debate in order to grasp trends.

Prime sources were: publications and websites of WHO and WHO Euro, OECD, European Commission, Health Canada and the Canada Research Chairs in the area of HHR as the leading international experts in the field; 2. conducting a literature search, comprising electronic data base searches in PubMed and SSCI, using the keywords defined in Box 1; exclusion criteria were: developing countries, and US. A more focused handsearch was added; prime sources were: publications of the European Observatory of Health Systems and Policies and WHO Euro; the international journals: Human Resources for Health; Health Policy; Health Services Research; Journal of Health Services Research and Policy; 3. systematising personal experiences of the authors and active participation in leading European organisations and research networks that allowed gathering expert information from a wide range of sources, mainly comprising: health workforce planning in the Netherlands led by NIVEL; health labour market monitoring and planning models in the federal states of Hessen and Rhineland Palatine in Germany; consultancy and research collaboration with WHO Euro and the European Observatory on Health Systems and Policies; membership in EU research networks, such as the FP7 COST action on 'Medicine and Management'; European Health Management Association (EHMA) Working Group on 'Health Workforce'; and European Public Health Association (EUPHA) section on 'Health Services Research'.

\section{MAPPING THE FIELD OF HHR POLICY}

The emergence of HHR policy (as defined in Box 1) is a new development. Until recently, issues of the health workforce were rarely recognised as specific area of health policy but limited to traditional forms of HR management and personnel administration, and dominated by workforce planning focussing exclusively on doctors [36]. The modern term health human resources policy became first known as 'manpower planning' in the 1970s and early 1980s in North America and was mainly driven by programmes and workshops organised by WHO [37,38]. A wave of planning models and publications appeared during these decades, followed by a 
Kuhlmann, E., Batenburg, R., Groenewegen, P.P., Larsen, C. Bringing a European perspective to the health human resources debate: a scoping study. Health Policy: 2013, 110(1), 6-13

period in which HHR planning was criticised and notably became a less important area of research and policy [39]. In Europe, 'manpower planning' also emerged in the late 1970s, but more fully developed in recent years and also reflected a broader scope than planning [26].

The emergent field of HHR policy has brought about transformations of the concept and has raised new questions.

Most obviously, in line with WHO and European non-sexist language policies, the term 'manpower planning' is increasingly replaced. However, transformations are not just a matter of language. They also reflect such issues as the gender composition of the health workforce, hierarchy within the occupational structure of healthcare and the restricted effectiveness of top-down initiatives.

We also observe a substantive broadening of the concept of HHR management (Box 1), now including linkages with (social) governance, (organisational) innovation and (personal) development [21,40,41]. Similarly, with regard to planning there is a "reemerging interest in workforce planning methods and techniques, that go beyond extrapolating past staffing trends but rather taking into account the changing demands for, and needs of, the health workforce of the future”, as Wismar et al. [3, p. 4] highlight in their European study [42-44].

According to a recent Policy Brief of the European Observatory on Health Systems and Policies, four different approaches are relevant to HHR planning:

- the health worker to population ratio; this is the simplest and most commonly used;

- the utilisation and demand approach;

- the service-target approach, that provides insight in tasks and skills required to deliver specific interventions; and

- the health and service needs approach [27].

A number of Canadian authors have been highly influential in developing planning models, based on the health and service needs approach. Following Birch et al. [45], these models define that future demand for health human resources basically depends on four elements:

- the size and demographic mix of the population (demography),

- the levels of risks to health and morbidity in the population (epidemiology),

- the services deemed appropriate to address the levels of risks to health and morbidity (standards of care), and

- the rate of service delivery by providers (productivity) [45].

The Policy Brief of the European Observatory on Health Systems and Policies acknowledges that the health and service needs approach is the most complex, as it requires a definition of 'service needs', in function of age and sex-specific morbidity trends, patient preferences and of service norms, and a conversion of this to staff requirements, using professionally defined productivity norms [27, p. 9]. One step more complicated is taking into account skill-mix and team approaches to HHR management.

It is interesting to see that this strand of HHR planning reflects the general health policy aims to shift the focus from supply-led towards more demand-led and responsive healthcare systems. It also acknowledges that the educational and 
Kuhlmann, E., Batenburg, R., Groenewegen, P.P., Larsen, C. Bringing a European perspective to the health human resources debate: a scoping study. Health Policy: 2013, 110(1), 6-13

occupational structures in healthcare are changing [43]. Yet it is important to recall here that needsbased HHR planning is originally shaped by advanced policy efforts in Canada. In the Canadian context HHR planning has been designed under the supply conditions of relatively high levels of immigrant health professionals and low population density; it is furthermore shaped by a decentralised system of provincial and territorial insurance schemes that is supported by loose national coordination $[13,16]$. Therefore, it is not evident if and how this approach can be applied to European HHR policy and whether this model serves best the European conditions. In their Policy Brief, Dussault et al. bring another key problem of HHR planning into perspective. Despite the availability of more complex models since a decade or so, HHR policy, where it exists, typically focuses on "establishing training numbers and related costs, rather than developing a comprehensive strategy covering compensation, working conditions, recruitment and retention issues” [27, p. 6]. The authors also recall that any strategy chosen for assessing HHR is value-based and shaped by the targets and "service objectives that policy-makers have set" [27, p. iv]. Hence, a needs-based approach is not only a complex statistical exercise that delivers the empirical evidence. It is influenced (and may even be 'manipulated') by policy and politics, including lobbying and strategic action of professional groups, healthcare organisations such as hospitals, and insurance bodies. A more critical and reflective discussion of approaches to HHR policy is therefore called for. In sum, the original idea of manpower planning has become part of more complex HHR policy, and different approaches to health workforce planning have become available. The question ignored so far, however, is as to whether and how these concepts and models are used in practice in the European context. The design and implementation of HHR policy is context specific. Consequently, an important challenge is to understand the conditions that influence the translation of existing approaches into European policy and practice. Here the values, targets, resources and governance arrangements of the healthcare systems in different countries come into play as well as supra-national regulation. This calls for context-sensitivity and feasibility of planning exercises. With this in mind, we next describe what HHR approaches can be found, and are studied, in Europe.

\section{WHERE ARE WE NOW IN HHR POLICY AND RESEARCH IN EUROPE?}

Health human resources have clearly moved up on the agenda of European policy [3,26,27,29,46-49]. Many European Union member states are investing to get HHR management practices in place and some country-specific planning models also exist [50]. Drawing on different approaches and data sources, a rapidly growing body of statistical data and research has emerged that is used for estimating and predicting shortages of qualified healthcare staff $[3,5]$. While these developments are promising and relevant, five critical limitations occur that hinder HHR policy and research in Europe.

First, European data sources on HHR are fragmented and heterogeneous; crossnational research is confronted with many difficulties in comparability of data, indicators and measurement methods. Even basic health occupational classifications often do not match between countries [51].

Second, much of the current research focuses on physicians and on specific sectors, such as hospitals or primary care; generalists or specialists. Examples of these include an overview of workforce trends in medical specialties in different countries 
Kuhlmann, E., Batenburg, R., Groenewegen, P.P., Larsen, C. Bringing a European perspective to the health human resources debate: a scoping study. Health Policy: 2013, 110(1), 6-13

[48,52], general practitioners workforce planning [53] or physician supply planning [51,54]. A complication of HHR data on physicians is that available data may also be influenced by the medical professions' interests [55]. In contrast to the centrality of physicians in HHR planning, only few studies include the biggest category in the health workforce: nurses [30]. In general, a wide range of health professional groups is missing from the HHR policy agenda.

Third, only a few studies on Europe move beyond mere numbers of health professionals (steady state analysis) and address dynamics and intersecting changes in the health workforce. This has become an important limitation, as it does not support HHR policies and management attempting to change the skill-mix of the health workforce and to shift tasks between physicians and nurses as well as between hospital care and primary care $[31,46,56]$. In a similar vein, changing sex ratios in the medical profession are increasingly mentioned in HHR planning, while at the same time more complex issues of gender relations are ignored [57].

Fourth, monitoring of migration in general, and intra- European mobility in particular, is increasingly gaining recognition in HHR policy, but research is still in a developmental stage. Again, existing monitoring systems and data sources often focus on physicians $[3,49]$, although the opening and globalisation of the European health labour market may cause even more problematic effects in the nursing profession [23,58,59].

Fifth, the focus on controlling training inflow is identified by Dussault et al. [27] as major limitation of HHR policy. For instance, Stordeur and Leonard [60], in their comparative study of HHR planning in Belgium, focused mainly on the failure of the numerus clausus system.

This system to control the inflow in medical training was introduced in Belgium to improve recurrent challenges, such as specialty imbalances, geographical misdistribution and movement of healthcare workers throughout the open European workforce market. A study by Reamy et al. [61] described supply trends in the medical workforce and planning efforts in the former communist countries. According to this study, after the collapse of the USSR, planning of the future physician workforce was used as a tool for correcting the excess supply, especially of medical specialists (according to EU standards) by reducing the entrance in medical schools, next to shifting the specialist workforce towards a primary care oriented workforce [for Lithuania, 62,63].

In the next section we sketch a road that helps to overcome these limitations and that is not concerned with specific labour market segments, individual countries and regions, but rather with furthering an integrated, European approach.

\section{OVERCOMING THE LIMITATIONS OF HHR POLICY: THE CHALLENGES OF INTEGRATED APPROACHES}

The previous section has highlighted a lack of integrated approaches as a key problem of managing HHR more effectively [39,44,64,65]. Yet 'integration' needs further investigation when applied to HHR policy. We have identified five major dimensions of integration which are related to the challenges of HHR policy and management as described above: 1 . system integration: connectedness between the educational system and the health labour market, and between the latter and broader labour market developments; 2. occupational integration: the inclusion of nurses and a wider range of health professional groups and the dynamics enhanced by new skill- 
Kuhlmann, E., Batenburg, R., Groenewegen, P.P., Larsen, C. Bringing a European perspective to the health human resources debate: a scoping study. Health Policy: 2013, 110(1), 6-13

mix and task-shifting policies in HHR governance; 3. sector integration: the balanced development of primary care and prevention, hospital and specialised care, and mental healthcare; 4 . gender cuts across these areas of integration: improving labour market chances, equality within and between professional groups, organisations and sectors of the healthcare system in order to reduce the gendered hierarchy that underpins the health professional workforce and care work; 5. socio-cultural integration: understanding the dynamics of migration and inter-European mobility in the health workforce.

\subsection{System integration}

To begin with the first type of integration, a recent WHO [11] document highlights the need for complex transformation in the educational system of health professionals in order to improve services. Further, Frenk et al. [4] argue for a multiprofessional and macro-institutional approach in order to improve the connections between the educational system and the health labour market; in their view, the health labour market is a sub-system that connects the provision of educational services with the supply of an educated workforce to meet the future demand for health professionals. The authors argue that the professional education sub-system is not capable of meeting future demand. Mismatches are systemic and include various different problems: mismatch of competencies to patient and population needs; lack of teamwork; the gender stratification of professional status; and the predominant hospital orientation at the expense of primary care [4, p. 1923].

More complex approach: "The project RN4CAST aims innovative forecasting methods by addressing not only volumes, but quality of nursing staff as well as quality of patient care“[30, p. 8]. Broadening the focus towards nursing is especially relevant when taking recent health policies and changes in the organisation of care into account. These include task-shifting from physicians to nurses, an increasing relevance of primary care and collaborative care, and new challenges of nurse migration [28,46,56,58,66-68].

To achieve occupational integration, the complexity of the occupational structure and the dynamic relationships between professions should be reflected in HHR policy in Europe.

\subsection{Sector integration}

HHR policy often focuses specific sectors of the healthcare system and planning is undertaken separately but embodies the interdependencies between sectors. Comparable healthcare needs can be addressed in different parts of the healthcare system, depending on the structure of the system and the role of gate-keeping professionals or needs assessment procedures. Thus, broader health system changes might affect the need for different types of health professionals in specific sectors. At the same time, professionals will move between sectors, depending on the availability and attractiveness of positions, including financial incentives and other forms of governing.

\subsection{Gender integration}

Compared to occupational integration much the same problems occur with respect to changing gender arrangements in the health workforce. For instance, the usual assumption is that growing numbers of female doctors will bring about a decrease in the average work hours due to higher caring responsibilities of women, and this in 
Kuhlmann, E., Batenburg, R., Groenewegen, P.P., Larsen, C. Bringing a European perspective to the health human resources debate: a scoping study. Health Policy: 2013, 110(1), 6-13

turn calls for higher inflow in medical schools. However, change in working hours is not only driven by women doctors but also by new work-life models of male doctors; and parenthood may not be the most relevant factor to predict work arrangements of women [69,70]. Another example of complex gendered dynamics is the horizontal and vertical gender segregation of the health professional workforce that may intersect with changing organisational settings. In Germany, for instance, public and private hospitals differ in the percentage of women doctors in leadership positions as well as in the skill-mix of doctors and nurses. Increasing privatisation of hospitals may therefore also impact in the gendered composition of the health workforce [71].

\subsection{Socio-cultural integration}

Health workforce migration research often focuses on the negative effects of 'brain drain' [8,12,72-74] or/and the economic efficiency for the host country [24]. While these are important issues, they do not adequately mirror the situation of many European countries that are primarily aiming at a self-sufficient workforce. It should be recalled that international recruitment has never been executed to the same extent - as a policy to respond to staff shortages - as it is known from the Anglo-American countries [75,76; for an overview, see www.compass.ox.ac.uk]. For instance, in 2007 the United Kingdom had more foreign physicians than all other European countries for which figures were available (Austria, France, Germany, Ireland, Italy, Norway, Poland, Portugal) [17]. There may also be qualitative differences in the efficiency of recruitment policies, as a comparison between nurse migration patterns in Canada and Finland reveals [58].

The creation of an open European labour market has brought about a new situation that has facilitated mobility within the European Union and its neighbours [3,77]. The problem is not per se an outflow of health professionals, but the uneven relationship between inflow and outflow [3,17]. Eastern European countries are becoming an important source of physicians and nurses for healthcare systems in the West, but do not equally benefit from increased mobility. Migration and mobility also intersect with other dynamics in the health labour market and societies at large. For example, 'gendered push-and-pull factors' are increasingly relevant in low status segments of the nursing profession but may also impact in the medical profession, and they intersect with geo-political and socio-economic inequalities in Europe [58,78].

In a similar vein, doctors and nurses from Eastern and central European countries often face economic discrimination and are trapped into lower status professional segments with limited, if any career chances and may even be denied permanent work permit; the situation is most alarming in a less regulated labour market, such as that of long-term care [79]. These developments not only reinforce ethnic discrimination within Europe and may nurture racism; they also counteract the HHR goals of more efficient use of existing skills and reliable planning, because discrimination increases the likelihood of drop-outs and moves to other countries $[12,14,72,78]$. Therefore, sustainable HHR planning is closely linked to improved socio-cultural and ethnic integration.

There are also several (western) countries with a more balanced situation between inmigration and outmigration of physicians, as for instance Germany [80].

Mobility flows may also help responding more flexibly to the failures of national education and labour market steering. One example of this is the temporary mobility flow of Austrian physicians in training for specialisation to (eastern) Germany [55]. 
Kuhlmann, E., Batenburg, R., Groenewegen, P.P., Larsen, C. Bringing a European perspective to the health human resources debate: a scoping study. Health Policy: 2013, 110(1), 6-13

Thus, intra- European mobility and migration may create risks as well as benefits for the healthcare systems and accelerate dynamics in the health labour market, which are not comparable to countries outside the European Union.

\section{CONCLUSIONS}

This scoping study has set out the need to bring a European perspective to the HHR debate. We have drawn state-of-the-art research together, sketched its limitations and have highlighted the challenges of furthering integration in the field of HHR policy in Europe. Our analysis now provides a more systematic basis on which to review the opportunities of a European HHR approach and to map out the way forward in researching HHR through a European lens.

First and foremost, HHR planning has to be integrated planning. This clearly calls for an end to mono-professional, primarily doctor-centred, 'gender-neutral' and socioculturally ignorant planning exercises, built on widespread sectorial fragmentation and 'methodological nationalism'.

Although the different types of integration are increasingly acknowledged in HHR policy, they are much less so in HHR management and planning; none of the existing HHR planning models responds adequately to the challenges that we have described in this article. This subsequently raises the questions, how complex integrative HHR planning models can/should be. How to define the balance between different planning goals and 'affordable' and manageable data, and between contextsensitivity and country comparability of HHR planning approaches? Increasing the analytical complexity of HHR planning models probably does not automatically bring about more reliable and efficient planning. Limitations apply, among other things, because these models are highly contextdependent with regard to their fit with the institutions and policy approaches of the healthcare system, the educational and occupational systems and the availability of reliable and complete data. Our own experience in HHR planning in Germany and the Netherlands has taught us that even basic categories and indicators, such as the number of physicians or nurses, do not easily match across countries.

What conclusions should be drawn if the analytical complexity of (even the most complex) needs-based HHR planning approaches [7,45] comes to its limits when confronted with the need for system, sectorial, occupational, gender and sociocultural integration? It is important to understand an urgent need for a European perspective that is capable of departing from the internationally observed trend (pioneered by Canada, but partly also the Netherlands) to deepen the analytical complexity of HHR planning models. Following the pathways of (otherwise important and innovative) currently dominant HHR models would inevitably lead to paradoxical blockades or a zero-sum outcome between increased complexity and decreased context-sensitivity, when applied to the institutional and socio-cultural diversity of Europe.

The way forward in European HHR planning is more likely to be efficient if we go precisely in the other direction and broaden the approaches. The current state of knowledge of the European situation and the comparative modelling methodology in our view is not sufficiently developed for establishing a European approach but the following steps might be helpful: understanding how institutions matter and bringing diversity and context-sensitivity into HHR planning are key issues in order to develop innovative approaches that use existing resources more creatively. For 
Kuhlmann, E., Batenburg, R., Groenewegen, P.P., Larsen, C. Bringing a European perspective to the health human resources debate: a scoping study. Health Policy: 2013, 110(1), 6-13

instance, a case study design of loosely linked single country research and/or smallscale comparative research can be used efficiently to facilitate an interaction between a European approach and national planning approaches. Also from a practical point of view, 'bottom-up' designed planning exercises that draw on comparative (national or regional) case studies may help us using existing data sources more efficiently and to fill some of the most urgent gaps in HHR policy and management.

The promising way forward is currently most likely a mix of European, national and regional comparative approaches that are:

- European in designing the outlines of better integrated planning approaches that take as much as possible the integration challenges described in this article into account;

- national in trying out and filling in these outlines for the situation in specific countries; and

- regional/local in building on case studies in order to begin with affordable research and pilot context-sensitive approaches.

Yet the search for policy-relevant, intermediate and feasible solutions should not lead is to give up lobbying for large scale cross-country research that is inevitably needed in order to develop a conceptual approach and reliable empirical data.

\section{CONFLICT OF INTEREST}

The authors declare that they have no conflict of interests.

\section{ACKNOWLEDGEMENTS}

We wish to thank our colleagues in various different research networks and collaborative projects for valuable discussions and for sharing and supporting our attempts towards furthering European HHR research. We are also thankful to colleagues at NIVEL who commented on an earlier version and to two anonymous reviewers of Health Policy for their very helpful comments.

\section{REFERENCES}

[1] OECD. The looming crises in the healthcare workforce. How can OCED countries respond? Paris: OECD Publishing; 2008.

[2] WHO. The World Health Report 2006 - working together for health.

Geneva: WHO; 2006.

[3] Wismar M, Glinos IA, Maier CB, Dussault G, Palm W, Bremner J, et al.

Health professional mobility and health systems: evidence from 17 European countries. Euro Observer 2011;13(2):1-4.

[4] Frenk J, Chen L, Bhutta ZA, Cohen JJ, Crisp LN, Evan TG, et al.

Health professionals for a new century: transforming education to strengthen health systems in an interdependent world. Lancet 2010;376:1923-58.

[5] Commission of the European Communities. Green Paper on the European Workforce for Health; 2008. Brussels, 10.12.2008, COM (2008) 725 final.

[6] European Parliament. Written Declaration, to the Rule 123 of the Rules of Procedure on the EU Workforce for Health, lapse date 17.9.2010, Brussels, 0040/2010; 2010.

[7] Dal Poz MR, Gupta N, Quain E, Soucat ALB, editors. Handbook on monitoring and evaluation of human resources for health. Geneva: WHO; 2009.

[8] Dumont JC, Zurn P. Immigrant health workers in OECD countries in the broader context of high skilled migration. In: International Migration Outlook, SOPEMI 2007 edition Paris: OECD; 2007 http://www.oecd.org/dataoecd/22/32/41515701.pdf [9] Martineau T, Willetts A. 
Kuhlmann, E., Batenburg, R., Groenewegen, P.P., Larsen, C. Bringing a European perspective to the health human resources debate: a scoping study. Health Policy: 2013, 110(1), 6-13

The health workforce: managing the crisis ethical international recruitment of health professionals: will codes of practice protect developing country health systems? Health Policy 2006;75:358-67.

[10] WHO. Models and tools for health workforce planning and projections. Geneva: WHO; 2010 http:// whqlibdoc.who.int/publications/2010/9789241599016 eng.pdf [11] WHO. Transformative scale up of health professional education.

Geneva: WHO; 2011 http://whqlibdoc.who.int/hq/2011/ WHO HSS HRH HEP2011.01 eng.pdf [12] Arah OA, Ogbu UC, Okeke CE. Too poor to leave, too rich to stay: developmental and global health correlates of physician migration to the United States, Canada, Australia, and the United Kingdom. American Journal of Public Health 2008;98(1):148-54.

[13] Birch S, Bourgeault IL, editors. Health human resources research in Canada. Canadian Public Policy 2007;33(Suppl):S1-99.

[14] Bourgeault IL, Atanackovic J, LeBrun J, Parpia R, Rashid A, Winkup J. The role of migrant care workers in ageing societies: the Canadian context and experience. Ottawa: COMPAS 2009, http://www.compas.ox.ac.uk [15] Cangiano A, Shutes I, Spencer S, Leesopn $\mathrm{G}$. The role of migrant care workers in ageing societies: research findings in the United Kingdom.

Oxford: COMPAS; 2009 http://www.compas.ox.ac.uk [16] Dumont JC, Zurn P, Church J, Le Thi C. International mobility of health professionals and health workforce management in Canada: myth and realities. OECD Health Working Paper No. 40, DELSA/ELSA/WP2/HEA(2008)6. Paris: OECD; 2008.

[17] García-Pérez MA, Amaya C, Otero A. Physicians' migration in Europe: an overview of the current situation. BMC Health Services Research 2007;7:201.

[18] Health Canada. A framework for collaborative pan-Canadian health human resources planning. Ottawa, ON: Health Canada; 2007.

[19] Imison C, Buchan J, Xavier S. NHS workforce planning: limitations and possibilities. London: King's Fund; 2009.

[20] Runnels V, Labonté R, Packer C. Reflections on the ethics of recruiting foreign trained human resources for health. Human Resources for Health 2011;9:2.

[21] Schofield T. Gendered organizational dynamics: the elephant in the room for Australian allied health workforce policy and planning.

Journal of Sociology 2009;45:383-400.

[22] Murphy GT, Birch S, MacKenzie A, Alder R, Lethbridge L, Little L. Eliminating the shortage of registered nurses in Canada: an exercise in applied needs-based planning. Health Policy 2012;105(2-3):192-202.

[23] Walsh K, O'Shea E. The role of migrant care workers in ageing societies: context and experiences in Ireland. Galway: Irish Centre for Social Gerontology; 2009 http://www.compas.ox.ac.uk [24] Young R, Noble J, Mahon A, Maxtred M, Grant J, Sibbald B.

Evaluation of international recruitment of health professionals in England. Journal of Health Services Research and Policy 2010;15(4): 195-203.

[25] WHO. The WHO global code of practice on the international recruitment of health personnel. Geneva: WHO; 2010 http://www.

who.int/hrh/migration/code/code en.pdf [26] Dubois C-A, McKee M, Nolte E. Human resources for health in Europe.

Berkshire: OUP; 2006.

[27] Dussault G, Buchan J, Sermeus W, Padaiga Z. Assessing future health workforce needs. In: Policy Summary 2. WHO, on behalf of European Observatory on Health Systems and Policies; 2010.

[28] Hansen J, Schäfer W, Black N, Groenewegen PP. European priorities for research on health care organizations and service delivery. Journal of Health Services Research and Policy 2011;16(Suppl 2):16-26.

[29] Rechel B, Dubois C-A, McKee M, editors. The health care workforce in Europe: learning from experience.

Copenhagen: WHO Regional Office for Europe; 2006. 
Kuhlmann, E., Batenburg, R., Groenewegen, P.P., Larsen, C. Bringing a European perspective to the health human resources debate: a scoping study. Health Policy: 2013, 110(1), 6-13

http://www.euro.who.int/Document/E89156.pdf [30] RN4CAST, Sermeus W, Aiken LA, Van den Heede K, et al. Nurse forecasting in Europe (RN4CAST): rationale, design and methodology.

BMC Nursing 2011;10:6.

[31] Van den Heuvel A, Aarendonk D, Groenewegen PP, De Maeseneer J.

The European Forum for Primary Care and the European Commission consultation on the European workforce for health: some emerging messages. Quality in Primary Care 2009;17:307-9.

[32] Arksey H, O'Malley L. Scoping studies: towards a methodological framework. International Journal of Social Research Methodology 2005;8:19-32.

[33] Brien SE, Lorenzetti DL, Lewis S, Kennedy J, Ghali WA. Overview of a formal scoping review on health system report cards. Implementation Science 2010;5:2.

[34] Burau $\mathrm{V}$. Methodological challenges of comparative health policy.

Current Sociology 2012;60(4):569-78.

[35] Busse R. Editorial. Methods in health systems and policy research. Health Policy 2012;104:205.

[36] Dussault G, Dubois CA. Human resources for health policies: a critical component in health policies. Human Resources for Health 2003;1:1.

[37] Hall T, Mejia A, editors. Health manpower planning: principles, methods, issues. Geneva: WHO; 1978.

[38] Steinwachs DM, Weiner JP, Shapiro S, Batalden BSP, Coltin K, Wasserman F. A comparison of the requirements for primary care physicians in HMOs with projections made by the GMENAC. New England Journal of Medicine 1968;314:217-22.

[39] Dreesch N, Dolea C, Dal Poz M, Goubarev A, Adams O, Aregawi M, et al. An approach to estimating human resource requirements to achieve the Millennium Development Goals. Health Policy and Planning 2005;20(5):227-67.

[40] Dieleman M, Shaw DMP, Zwanikken P. Improving the implementation of health workforce policies through governance: a review of case studies. BMC Human Resources for Health 2011;9:10.

[41] Dubois C-A, Singh D. From staff-mix to skill-mix and beyond: towards a systemic approach to health workforce management. BMC Human Resources for Health 2009;7:87.

[42] Birch S, O'Brien-Pallas L, Alksnis C, Tomblin Murphy G, Thomson D. Beyond demographic change in human resources planning: an extended framework and application in nursing. Journal of Health Services Research and Policy 2003;8:225-9.

[43] Groenewegen PP, Plochg T, Batenburg R. De beroepen-en opleidingsstructuur van de Nederlandse gezondheidszorg; passend voor de toekomstige zorgvraag? In: Bakker DJ, Polder J, Post D, editors. Een vitale toekomst. Onze gezondheidszorg in 2040. Den Haag: Elsevier, 2012. p. 202-208.

[44] Murphy GT, Kephart G, Lethbridge L, O'Brien-Pallas L, Birch S.

Planning for what? Challenging the assumptions of health human resources planning. Health Policy 2009;92(2):225-33.

[45] Birch S, Kephart G, Murphy GT, O'Brien-Pallas L, Alder R, Mackenzie A. Health human resource planning and the production of health: development of an extended analytical framework for needs-based health human resources planning. Journal of Public Health Management Practice 2009; November (Suppl):S56-61.

[46] Bourgeault IL, Kuhlmann E, Neiterman E, Wrede S. How to effectively implement optimal skill-mix and why? In: Policy Brief Series. WHO Europe; 2008 http://www.euro.who [47] Dubois C-A, McKee M. Cross-national comparisons of human resources for health: what can we learn? Health Economics, Policy and Law 2006;1:59-78.

[48] Euro Observer. The Health Policy Bulletin of the European Observatory on Health Systems and Policies. 2010;12(2).

[49] Euro Observer. The Health Policy Bulletin of the European Observatory on Health Systems and Policies. 2011;13(2).

[50] RGO - Advisory Council on Health Research. Health services research: the future of health services research in the Netherlands.

The Hague: Health Council of the Netherlands; 2008. RGO 59E http://www.rgo.nl [51]

Roberfroid D, Stordeur S, Camberlin C, Voorde C, Vrijens F, Léonard C.

Physician workforce supply in Belgium: current situation and challenges. 
Kuhlmann, E., Batenburg, R., Groenewegen, P.P., Larsen, C. Bringing a European perspective to the health human resources debate: a scoping study. Health Policy: 2013, 110(1), 6-13

Brussels: Belgian Health Care Knowledge Centre (KCE); 2008.

[52] Barber P, González López-Valcárcel B. Forcasting the need for medical specialists in Spain: application of a system model. Human Resources for Health 2010;8:24.

[53] Teljeur C, Thomas S, O'Kelly FD, O'Dowd T. General practitioner workforce planning: assessment of four policy directions. BMC Health Services Research 2010;10:148.

[54] Roberfroid D, Leonard C, Stordeur S. Physician supply forecast: better than peering in a crystal ball? BMC Human Resources for Health 2009;7:10.

[55] Kopetsch T. Dem deutschen Gesundheitswesen gehen die Ärzte aus! Studie zur Altersstruktur und Arztzahlentwicklung. Berlin: Bundesärztekammer und Kassenärztliche Bundesvereinigung; 2010.

[56] Groenewegen PP. Nursing as grease in the primary care machinery.

Quality in Primary Care 2008;16:313-4.

[57] Kuhlmann E, Bourgeault IL, Larsen C, Schofield T. Gendering health human resource management and policy. In: Kuhlmann E, Annandale E, editors. The Palgrave handbook of gender and healthcare, second edition Basingstoke: Palgrave; 2012. p. 72-91.

[58] Bourgeault IL, Wrede S. Caring beyond borders: comparing the relationship between work and migration patterns in Canada and Finland. Canadian Journal of Public Health 2009;99(S2):S22-6.

[59] Stubnya G, Csetneki J, Balogh Z. Nurses in Hungary: an analysis of the decline in staffing levels. Eurohealth 2011;17(1):14-6.

[60] Stordeur S, Leonard C. Challenges in physician supply planning: the case of Belgium. Human Resources for Health 2010;8:28.

[61] Reamy J, Lovkyte L, Padaiga Z. Physician workforce planning and the transition to primary health care in former socialist countries. Cahiers de Sociologie et de Démographie Médicales 2005;45(2-3):307-25.

[62] Liseckiene I, Boerma WG, Milasauskiene Z, Valius L, Miseviciene I, Groenewegen PP. Primary care in a post-communist country 10 years later, Comparison of service profiles of Lithuanian primary care physicians in 1994 and GPs in 2004. Health Policy 2007;83(1):105-13.

[63] Starkiene L, Smigelskas K, Padaiga Z, Reamy J. The future prospects of Lithuanian family physicians: a 10-year forecasting study. BMC Family Practice 2005;6:4.

[64] Masnick K, McDonnell G. A model linking clinical workforce skill mix planning to health and health care dynamics. Human Resources for Health 2010;8:11.

[65] O'Brien-Pallas L, Birch S, Baumann A, Murphy GT. Integrating workforce planning, human resources and service planning. Geneva: WHO; 2001.

[66] Buchan J, Calman L. Skill-mix and policy change in the health workforce: nurses in advanced roles. OECD Health Working Paper No. 17; 2005. http://www.oecd.org [67] De Geest S, Moons P, Callens B, Gut C, Lindpaintner L, Spirig R.

Introducing advanced practice nurses/nurse practitioners in health care systems: a framework for reflection and analysis. Swiss Medical Weekly 2008;138:621-8.

[68] Buddeberg-Fischer B, Stamm M, Buddeberg C, Bauer G, Hämmig O, Knecht M, et al. The impact of gender and parenthood on physicians' careers. BMC Health Services Research 2010;10:40.

[69] De Jong J, Heiligers P, Groenewegen PP, Hingstman L. Why are some medical specialists working part-time, while others work full-time? Health Policy 2006;78:235-48.

[70] Kuhlmann E, Larsen C. Diversity Management und Arbeitskräftemanagement: Innovationspotenziale für Qualität und Effizienz im Gesundheitssystem. In: Badura B, Schröder H, Klose J, Macco K, editors.

Fehlzeitenreport. Berlin: Springer; 2010. p. 100-9.

[71] Dominiczak M. Of wandering doctors, cities, and humane hospitals.

Lancet 2010;377(9759):22-3.

[72] Martineau T, Decker K, Bundred P. "Brain drain" of health professionals: from rhetoric to responsible action. Health Policy 2004;70: 1-10.

[73] Zurn P, Diallo K, Kinfu J. Monitoring health workforce transitions and exits. In: Dal Poz MR, Gupta N, Quain E, Soucat ALB, editors. Handbook on monitoring and evaluation of human resources for health.

Geneva: WHO; 2009. p. 49-59. 
Kuhlmann, E., Batenburg, R., Groenewegen, P.P., Larsen, C. Bringing a European perspective to the health human resources debate: a scoping study. Health Policy: 2013, 110(1), 6-13

[74] Buchan J. How can the migration of health professionals be managed so as to reduce any negative effects on supply. In: Policy Brief Series.

WHO Europe; 2008 http://www.euro.who [75] Garrido MV. Specialists in Germany. Euro Observer 2010;12(2): 6-7.

[76] Mladovsky P, Leone T. Specialist human resources for health in Europe: are we ready? Euro Observer 2010;12(2):1-5.

[77] Goryakin Y, Griffiths P, Maben J. Economic evaluation of nurse staffing and nurse substitution in health care: a scoping review. International Journal of Nursing Studies 2011;48:501-12.

[78] Riska E, Novelskaite A. Professionals in transition: physicians' careers migration and gender in Lithuania. In: Kuhlmann E, Saks M, editors.

Rethinking professional governance: international directions in healthcare. Bristol: Policy Press; 2008. p. 217-30.

[79] Larsen C, Joost A, Heid S, editors. Illegal employment in Europe: the situation in private homes of the elderly. München: Rainer Hampp Verlag; 2009.

[80] Ognyanova D, Busse R. A destination and a source country: Germany.

Euro Observer 2011;2:5. 